\title{
Spatial differences of exergy use of cement manu- facturing industry in China based on extended exergy accounting method
}

\author{
CHEN Fengnan ${ }^{1,2}$, "SHEN Lei ${ }^{1}$, LIU Litao ${ }^{1}$, GAO Tianming ${ }^{1}$ \\ 1. Institute of Geographic Sciences and Natural Resources Research, CAS, Beijing 100101, China; \\ 2. University of Chinese Academy of Sciences, Beijing 100049, China
}

\begin{abstract}
Factory-level data from 23 provinces and some national statistical data in cement manufacturing industry and socio-economies in 2012 are used to analyze the spatial distribution of exergy use for China's cement manufacturing industry by the Extended Exergy Accounting method. This method takes full account of the inclusion of energy and raw material supply and other external factors (capital, labor and environment) into a comprehensive resource cost assessment. The extended exergy consumption and its intensity quantitatively at the provincial levels of cement production were calculated and then the agglomeration level of exergy use at the regional level was also evaluated. Based on this analysis, their spatial difference in size and efficiency of exergy use at the provincial level were identified. Moreover, their regional characteristics were revealed. Some important results could be drawn as follows. First, the invisible social cost accounted for $1 / 10$ of the total exergy use in cement manufacturing industry, while the energy element shared about 9/10. Second, the gross distribution of exergy use in China's cement manufacturing industry was mainly concentrated in the eastern region like Anhui and Shandong provinces, and in the western region like Sichuan province. In terms of exergy use, the coal and electricity were the highest of energy costs in the eastern region, whereas the cost of capital, labor and external environmental factors highlighted the invisible social cost for cement production in the central and western regions to some extent. Third, the efficiency distribution of exergy use in China's cement manufacturing industry illustrated an incremental feature from west to east, especially for the energy, labor and capital efficiencies. An evaluation on the environmental efficiency indicated that provinces or regions like Tibet, Xinjiang, Inner Mongolia and Shanxi have undertaken much higher environmental costs. Fourth, the 23 provinces could be classified into eight groups by the Euclidean distance model using the gross and efficiency results of exergy use. Fifth, the high industry concentration degree is the main driving factor of exergy efficiency improvement for cement manufacturing industry in China.
\end{abstract}

Keywords: cement manufacturing industry; spatial difference; exergy use; extended exergy accounting method

Received: 2015-06-08 Accepted: 2015-07-15

Foundation: Strategic Priority Research Program of the Chinese Academy of Sciences, No.XDA05010400; National Natural Science Foundation of China, No.41271547, No.41401644

Author: Chen Fengnan (1988-), PhD, specialized in resources economy and policy. E-mail: chenfn.12b@igsnrr.ac.cn

"Corresponding author: Shen Lei (1964-), PhD and Professor, E-mail: shenl@igsnrr.ac.cn 


\section{Introduction}

Traditional energy research largely considered the quantity of energy, but rarely the quality of energy consumption. Recently, a new concept of energy consumption, namely "exergy," has been introduced. This is an important indicator to estimate the trade-off between maximum efficiency and minimum consumption. Nowadays, the very concept of "resource consumption" is undergoing a radical re-evaluation in response to the acknowledged interdependency of the energy sector with both the environment and society at large. Traditional research on "energy consumption" focused on the resource itself, while system analysts began distinguishing between energy and materials resources and labor and monetary inflows, initially from the biosphere-conscious approach (Costanza et al., 2002; Daly and Farley, 2012). In modern industrial societies, the monetary cost is a crucial decision variable. However, the limitations caused by the use of the monetary proxy have been known for some time because the evaluation of the costs is associated with many variables including the market, the character of the resource, and the environmental remediation activities. Valero et al. (1986) realized that if all fuels were attributed to an exergy cost rather than a monetary one, the cost of the final product would be represented in the same units $(\mathrm{J} / \mathrm{kg})$. Following this and based on the CExC (cumulative energy consumption) concept (Szargut et al., 1987), the formulation of the Extended Exergy Accounting method was provided (Sciubba, 2003) to address the problem of the inclusion of all externalities into an exergy based analysis, quantifying such consumption in units of exergy.

The cement manufacturing industry is not only one of the most important industries within national infrastructure construction but also an energy intensive industry that represents $2 \%-6 \%$ of all industries and $12 \%-15 \%$ of all manufacturing industries (Sogut et al., 2009). The production of cement requires $60-130 \mathrm{~kg}$ of fuel oil and $110 \mathrm{kWh}$ of electricity per ton of cement (International Energy Agency, 2010). As the largest cement producer in the world, China produced 2,184 million tons in 2012 (NBS, 2013), accounting for more than $50 \%$ of the global output. However, there is still an enormous gap between China and other advanced international producers. Overall, the average energy consumption for producing per ton of cement in China is $40 \%$ higher than those in other countries (Jebaraj and Iniyan, 2006), with coal consumption approximately $11 \%$ to $20 \%$ higher and the average electricity consumption $23 \%$ higher than overseas. Furthermore, emissions from cement production have a great impact on the environment, among which $\mathrm{CO}_{2}$ accounts for $99.2 \%$ of all emissions. Thus, China's cement industry is facing significant challenges and pressure in the era of sustainable development and low-carbon economies. Therefore, improving the level of sustainable growth is an inherent requirement for the development of China's cement industry.

Thus far, few studies on energy systems in industry have focused on cement manufacturing; relevant studies have generally investigated energy consumption from national and departmental levels. For example, Schuer and Ellerbrock (1992) calculated the energy consumption values of Germany's cement industry. Saxena et al. (1995) measured the energy consumption of India's cement industry and effective methods for energy reservation. Phylipsen et al. (1997) compared research methods for energy efficiency, using the cement industry as an example. Worell et al. $(2000,2003)$ conducted a thorough analysis of the US 
cement industry, listing a variety of appropriate technologies and methods to upgrade energy efficiency within the cement industry. Zeng (2006) estimated the energy saving capacity of different measures in China's cement industry. Qi (2010) summarized the difference between energy efficiency in China and abroad for both production lines and enterprises. Ali Hasanbeigi et al. (2010) investigated electricity consumption efficiency and fuel consumption efficiency in Thailand's cement industry using a CSC model, and conducted an economic analysis on energy conservation. Sogut (2012) described the variation trend of energy efficiency in Turkey's cement industry using clinker data. However, the afore-mentioned research and similar studies lack an in-depth analysis on spatial pattern and its discrepancies. Thereupon, this paper discusses the sustainability of the cement industry from a new perspective, not only quantifying natural resources but also translating externalities into cumulative exergetic costs. Furthermore, it provides an in-depth analysis into the provincial spatial discrepancy in China's cement manufacturing industry with a comprehensive extended exergy accounting (EEA)-based analytical paradigm, aiming to provide some reference for decision making in sustainable development and spatial distribution in China's cement industry.

\section{Data and methods}

\subsection{Data sources}

In the present study, input and output data such as the coal consumption of the enterprise, lower heating value (LHV), moisture content, temperature of the coal, electricity consumption, output of clinker, calculation of $\mathrm{CO}_{2}$ emissions and its temperature, are based on a large-scale sampling survey on cement production lines in China's 23 provinces. The survey includes a total of 339 production lines (170 NSP production lines, 75 shaft kiln production lines, 94 special cement production lines and grinding stations) and 1,755 samples.

The economic data including population, labor, wage and GDP come from the Economic Statistical Yearbook of People's Republic of China (NBS, 2013). The M2 (money supply that includes coins, notes, short-term time deposits) value is sourced from annual statistical data of the People's Bank of China (PBC, 2012), whereas that of each province is assessed according to its weight of GDP. Data on annual temperatures comes from the Climate Data of China sharing on the website (CDC, 2012), and Human Development Index (HDI) values are based on Hu B (2009).

Industry data for cement manufacturing mainly comes from the Cement Yearbook of People's Republic of China (CCA, 2006-2011), including the total output of clinker, number of employees, and the average benefit and wage per capita in the cement manufacturing industry. Unfortunately, data by province were absent in the 2012-2013 Yearbook; thus, we included 2012 data of clinker output from ASKCI (ASKCI, 2014) and estimated the number of employees and the average benefit and wage based on 2005-2010 data.

In 2012, China's total clinker output was 1278.54 billion tons; the output for the sample provinces was 1169.5 billion tons, accounting for $91.5 \%$ of all output. Thus, data from the provinces essentially represents China's clinker output. Therefore, in this study we describe the spatial distribution using the sample data. Additionally, the total energy consumption of the cement industry of every province is deduced by the proportion of clinker output in the 
sample production lines to its absolute clinker output.

\subsection{The EEA method}

The concept of EEA was first coined in 1998 (Rocco et al., 2014), with "extended" as a reminder that the resulting product cost includes not only materials and energy but also externalities, and it can be rewritten as follows:

$$
E E=C E_{x} C+E_{L}+E_{K}+E_{O}
$$

where $C E_{x} C$ represents the cumulative exergy consumption of natural resources, and labor, capital, and environmental cost contributions are expressed by means of their primary exergy equivalents, $E_{L}, E_{K}$, and $E_{O}$, respectively.

As a resource quantifier, the EEA method translates externalities (capital, labor and environmental remediation) into cumulative exergetic costs and thus allows for their rigorous inclusion in a comprehensive resource cost assessment. Indeed, the extended exergy cost reflects both the thermodynamic "efficiency" of the machinery and the "hidden" resource cost to society. Likewise, because the equivalent exergy cost of the externalities depends on both the type of society and the time window of the analysis, the extended exergy cost reflects the "conversion efficiency" of the society within which the analysis is performed. Thus, the EEA method can provide both additional insight and more relevant information for every comparative analysis of energy conversion systems at a local level.

\subsection{Calculation of cumulative exergy consumption of natural resources}

In accordance with the calculation of a typical cement production line, the exergy of coal consumption is $2747.750 \mathrm{~kJ}$, the exergy of electricity consumption is $261.775 \mathrm{~kJ}$ and other resources (limestone, clay, gypsum, fly ash, etc.) is no more than $2 \mathrm{~kJ}$ per kilogram of cement. Therefore, coal and electricity are solely selected to calculate the cumulative exergy consumption:

$$
C E_{x} C=E_{a 1}+E_{a 2}+E_{b}
$$

where $E_{a 1}$ represents the combustion exergy of coal, $E_{a 2}$ is the sensible heat exergy of coal, and $E_{b}$ represents the exergy transformed by electricity. In analytical forms (Zhu, 1988):

$$
\begin{gathered}
E_{a 1}=h_{L, f}+C_{1} w \\
E_{a 2}=m \times C_{2} \times\left[\left(T-T_{0}\right)-T_{0} \times \ln \frac{T}{T_{0}}\right] \\
E_{b}=Q=N \times K \times \beta
\end{gathered}
$$

where $h_{L, f}$ is the LHV of the fuel, $C_{1}$ is the evaporation latent heat of moisture in the reference temperature, $w$ is the water content in the fuel, and $m$ is the mass flow rate of coal. Furthermore, $C_{2}$ is the specific heat of coal, $T$ is the temperature of coal, the subscript ' 0 ' denotes conditions of the reference environment, $Q$ is energy converted by electricity input, $N$ is the network inputted by electromotor, $K$ is the heat equivalent transferred by work, and $\beta$ is the transformation percentage of electricity. 


\subsection{Calculation of exergy consumption of externalities}

\subsubsection{Calculation of labor externality}

Assuming that all the members of a community thrive on the production of labor (Sciubba et al., 2008), the exergy embodied in labor is the fully utilized aspect (relative to the unemployed population). Thus, the formula employed in EEA to calculate labor in the cement manufacturing industry is:

$$
E_{L}=\gamma \cdot \alpha \cdot E_{\text {in }}=\gamma \cdot f \cdot e_{\text {surv }} \cdot N_{h}
$$

where $\gamma$ represents the proportion of labor in the cement manufacturing industry to the total labor within the entire society, $\alpha$ denotes the proportion of exergy embodied in labor to the net exergy input $\left(E_{i n}\right), f$ is a consumption amplifier factor, $N_{h}$ is the population numerosity, and $e_{\text {surv }}$ represents the minimum exergy amount required for the metabolic survival of an individual (approximately $1.05 \times 10^{7} \mathrm{~J} /($ person $\times$ day)) (Sciubba, 2011). The HDI is adopted here to estimate the amplification factor, where $H D I_{0}$ is the HDI of a pre-industrial society (approximately 0.005) (Seckin et al., 2012). The formulation is as follows:

$$
f=\frac{H D I}{H D I_{0}}
$$

\subsubsection{Calculation of capital externality}

Except for the first postulate that a portion of the gross global influx of exergy resources $E_{\text {in }}$ is used to sustain the workers who generate labor, there is another postulate that describes that the amount of exergy required to generate the net monetary circulation within a society is proportional to the amount of exergy embodied in labor (Sciubba, 2011). The formulation is as follows:

$$
E_{k}=\beta \cdot E_{L}=\alpha \cdot \beta \cdot E_{\text {in }}
$$

where $\beta$ indicates the capacity of a society to generate monetary circulation in addition to wage compensation as a "financial ratio" or "financial amplification factor" compared with gross cumulative wages. It can be computed as:

$$
\beta=\frac{M_{F}}{S}=\frac{M 2-S}{S}
$$

where $M_{F}$ represents the financial activities, $S$ represents gross cumulative wages, and $M 2$ represents the total quantity of circulating money and financial activities in the considered economic system. Similarly to $\alpha, \beta$ depends on the spatial context and on the considered time window, but also on the various socioeconomic parameters of the considered country.

\subsubsection{Calculation of environmental externality}

The calculation of environmental externalities using the EEA method consist in the calculation of the additional consumption of extended exergy that would enable the system to release effluent into the environment with zero exergy content, introducing an equilibrium with the environment using state-of-the-art processes. Thus, environmental costs can be calculated as:

$$
E_{0}=E E_{R P}+E_{\text {buffer }}
$$

where $E_{0}$ is the exergy equivalent of environmental costs, $E_{R P}$ is the extended exergy ab- 
sorbed by the effluent treatment system, and $E_{\text {buffer }}$ is the exergy expenditure of the environmental buffering capacity. However, the Second Law negates that any real system can emit effluent in perfect thermodynamic equilibrium with the surrounding environment. Thus, in the EEA method, the unavoidable residual exergy of the stream is charged to the buffering capacity of the environment $\left(E_{\text {buffer }}\right)$.

Because of the relatively few studies to date on carbon capture and storage costs, here we assume the surroundings can remove the exergy level of $\mathrm{CO}_{2}$ emissions by natural processes, and no extended treatment process is required. Thus, the environmental cost is equal to the exergy of the natural buffering, and the environmental cost of $\mathrm{CO}_{2}$ emission becomes:

$$
E_{\mathrm{CO}_{2}}=f_{\mathrm{CO}_{2}} \times m_{s} \times C_{\mathrm{CO}_{2}} \times\left[\left(T-T_{0}\right)-T_{0} \times \ln \frac{T}{T_{0}}\right]
$$

where $f_{\mathrm{CO}_{2}}$ represents the emission factor of $\mathrm{CO}_{2}(\mathrm{~kg} \mathrm{CO} / \mathrm{t}$ clinker $), m_{s}$ represents the total output of clinker, $C_{\mathrm{CO}_{2}}$ is the specific heat of $\mathrm{CO}_{2}$, and $T$ and $T_{0}$ represent the temperature of $\mathrm{CO}_{2}$ and environment, respectively. Thus, the results of Shen et al. (2014) are adopted to estimate the emission factor of $\mathrm{CO}_{2}$.

\subsection{Selection of influencing factors on exergy use in the cement manufacturing industry}

Based on previous studies (Zook, 2002; Doloreux and Shearmur, 2012; Cohen and Paul, 2005; Ghemawat and Thomas, 2008), nine indicators were selected to characterize the five influencing factors: scale, profit, investment, technology, and industry concentration. Among these factors, (a) scale reflects industry foundation and competition between enterprises, (b) profit affects the decision to expand market share and improve competitiveness, (c) investment is important in the construction of NSP production lines, (d) technology influences the development of cement manufacturing (especially regarding the energy efficiency of processes), and (e) industry concentration plays an important role in improving competitiveness (e.g., Japan and Mexico's cement industries, where high industry concentration helps to achieve resource integration). The following indicators are used to characterize the factors: the number of enterprises and the gross assets of an enterprise above a designated size (scale); the main operating revenue and the gross profit (profit); the fixed assets investment and the designed capacity of newly increased production line being invested (investment); number of technology patents in the cement manufacturing industry (technology); and the weight of clinker production capacity of the top 20 cement enterprises (N20) and the weight of clinker production capacity of the top 100 cement enterprises (N100) (industry concentration). These indicators were selected as potential driving forces influencing exergy use in the cement manufacturing industry in China.

\section{Results and Analysis}

\subsection{Spatial pattern of exergy use in cement manufacturing industry at the provincial level}

Extended exergy including energy, labor, capital, and environmental cost for China's 23 provinces in 2012 were calculated on the basis of relevant data and formulas (1)-(11). The 
results are shown in Table 1.

Table 1 Exergy consumption for cement production in 23 provinces in 2012 (trillion KJ)

\begin{tabular}{|c|c|c|c|c|c|}
\hline & $\begin{array}{c}\text { Extended exergy } \\
\text { (EE) }\end{array}$ & Energy exergy & Labor exergy & Capital exergy & $\begin{array}{c}\text { Environmental } \\
\text { cost exergy }\end{array}$ \\
\hline Anhui & 485.937 & 443.641 & 22.363 & 2.221 & 17.712 \\
\hline Shandong & 418.394 & 360.372 & 39.139 & 4.624 & 14.259 \\
\hline Sichuan & 403.122 & 328.768 & 52.613 & 8.921 & 12.820 \\
\hline Henan & 338.594 & 300.191 & 25.007 & 1.980 & 11.416 \\
\hline Guangxi & 298.105 & 255.748 & 25.554 & 6.342 & 10.462 \\
\hline Guangdong & 295.514 & 264.361 & 19.731 & 0.566 & 10.857 \\
\hline Hunan & 291.936 & 237.273 & 38.695 & 8.170 & 7.798 \\
\hline Hebei & 291.914 & 238.490 & 36.873 & 6.866 & 9.686 \\
\hline Yunnan & 290.653 & 261.074 & 20.333 & 1.838 & 7.408 \\
\hline Hubei & 279.172 & 244.959 & 22.515 & 3.054 & 8.644 \\
\hline Jiangsu & 262.285 & 226.601 & 25.161 & 2.313 & 8.210 \\
\hline Zhejiang & 254.440 & 236.305 & 8.794 & 0.194 & 9.147 \\
\hline Fujian & 229.120 & 214.621 & 7.529 & 0.286 & 6.684 \\
\hline Jiangxi & 227.888 & 193.742 & 22.709 & 4.482 & 6.956 \\
\hline Shaanxi & 211.176 & 188.898 & 14.276 & 1.165 & 6.837 \\
\hline Xinjiang & 207.209 & 191.190 & 9.618 & 0.541 & 5.860 \\
\hline Guizhou & 188.316 & 162.811 & 17.833 & 1.335 & 6.337 \\
\hline Inner Mongolia & 175.765 & 153.476 & 13.487 & 2.260 & 6.542 \\
\hline Liaoning & 171.575 & 151.771 & 12.875 & 0.880 & 6.049 \\
\hline Chongqing & 170.913 & 149.190 & 14.665 & 1.510 & 5.547 \\
\hline Shanxi & 154.046 & 137.738 & 10.657 & 0.391 & 5.260 \\
\hline Tibet & 21.865 & 19.796 & 1.478 & 0.099 & 0.491 \\
\hline Beijing & 18.369 & 16.754 & 0.654 & 0.001 & 0.960 \\
\hline
\end{tabular}

We can see that energy, labor, capital, and environmental cost have different spatial patterns (Figure 1). Energy extrudes in the eastern cluster, especially the Anhui core, whereas the radiation effect of the Sichuan core is relatively weak in the western cluster. Referring to labor, Hebei, Shandong, Sichuan, and Henan have the highest consumption levels, while Zhejiang, Fujian, and Guangdong (coastal provinces in the southeast) consume less labor exergy. With respect to capital, consumption in the eastern region is significantly less than that in the central and western regions (the capital cost of Sichuan in the west is far higher than that of Anhui in the east). Additionally, Hunan and Guangxi have high capital exergy, which is more prominent than in the other regions. The environmental cost is high in the cores of both clusters and highlighted in Guangdong and Guangxi.

Except for the total amount, intensity (exergy consumption of unit clinker) is used to characterize the efficiency of exergy use in the cement manufacturing industry; a high level of exergy intensity means low efficiency in exergy use. The results are shown in Table 2. 
(a)

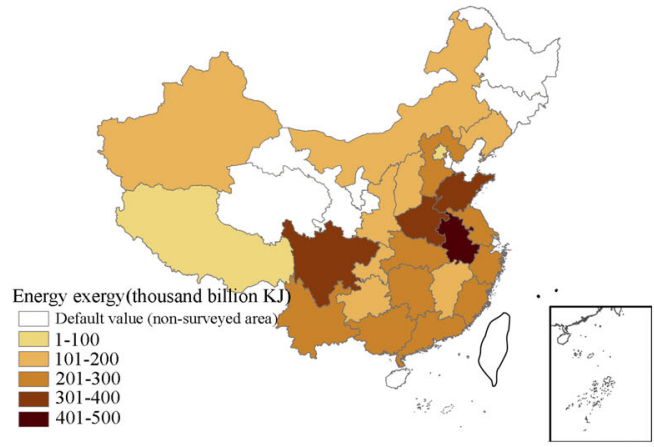

(c)

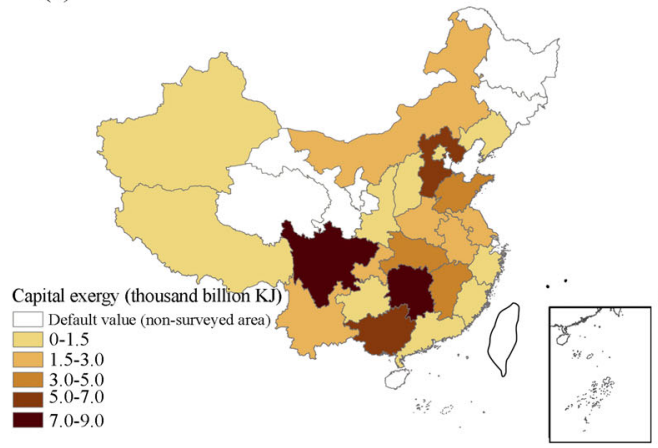

(b)

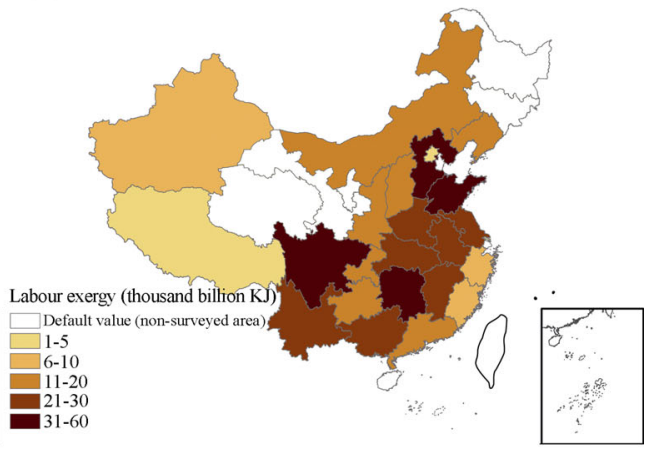

(d)

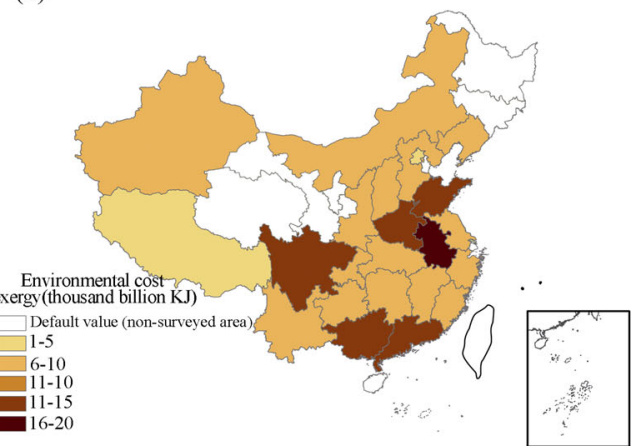

Figure 1 Spatial distribution of exergy consumption for cement production from energy, labor, capital and environmental costs in 2012 by province

Table 2 Exergy intensity for cement production in 23 provinces in $2012(\mathrm{KJ} / \mathrm{kg})$

\begin{tabular}{|c|c|c|c|c|c|}
\hline & $\begin{array}{l}\text { Extended ex- } \\
\text { ergy intensity }\end{array}$ & $\begin{array}{c}\text { Energy exergy } \\
\text { intensity }\end{array}$ & $\begin{array}{c}\text { Labor exergy } \\
\text { intensity }\end{array}$ & $\begin{array}{c}\text { Capital exergy } \\
\text { intensity }\end{array}$ & $\begin{array}{c}\text { Environmental cost } \\
\text { exergy intensity }\end{array}$ \\
\hline Tibet & 10339.752 & 9361.690 & 698.847 & 46.843 & 232.372 \\
\hline Xinjiang & 6256.840 & 5773.150 & 290.411 & 16.323 & 176.956 \\
\hline Hunan & 5496.197 & 4467.078 & 728.507 & 153.807 & 146.805 \\
\hline Yunnan & 5447.390 & 4893.027 & 381.086 & 34.443 & 138.834 \\
\hline Sichuan & 5215.048 & 4253.154 & 680.638 & 115.410 & 165.845 \\
\hline Shaanxi & 5160.090 & 4615.729 & 348.837 & 28.463 & 167.061 \\
\hline Shanxi & 5150.822 & 4605.546 & 356.344 & 13.063 & 175.870 \\
\hline Jiangsu & 5102.379 & 4408.192 & 489.477 & 45.004 & 159.705 \\
\hline Hubei & 5031.084 & 4414.514 & 405.759 & 55.041 & 155.770 \\
\hline Inner Mongolia & 5022.853 & 4385.894 & 385.427 & 64.591 & 186.941 \\
\hline Fujian & 4922.684 & 4611.174 & 161.752 & 6.144 & 143.613 \\
\hline Hebei & 4908.618 & 4010.269 & 620.022 & 115.448 & 162.880 \\
\hline Shandong & 4803.530 & 4137.393 & 449.347 & 53.089 & 163.701 \\
\hline Jiangxi & 4801.097 & 4081.713 & 478.424 & 94.417 & 146.543 \\
\hline Chongqing & 4795.631 & 4186.113 & 411.496 & 42.372 & 155.651 \\
\hline Henan & 4721.650 & 4186.137 & 348.714 & 27.607 & 159.191 \\
\hline Liaoning & 4648.038 & 4111.535 & 348.789 & 23.832 & 163.882 \\
\hline Zhejiang & 4487.138 & 4167.314 & 155.084 & 3.427 & 161.313 \\
\hline Guizhou & 4483.586 & 3876.349 & 424.588 & 31.782 & 150.867 \\
\hline Guangxi & 4389.202 & 3765.548 & 376.248 & 93.373 & 154.033 \\
\hline Anhui & 4371.883 & 3991.352 & 201.196 & 19.980 & 159.355 \\
\hline Guangdong & 4301.659 & 3848.172 & 287.214 & 8.237 & 158.036 \\
\hline Beijing & 2842.496 & 2592.588 & 101.171 & 0.113 & 148.625 \\
\hline
\end{tabular}


Regarding energy efficiency, Beijing is ahead of the other provinces (Figure 2), whereas Tibet and Xinjiang fall behind because of a lag in technology, low degree of industry concentration, and numerous other factors. The exergy intensity value of hidden social cost shows that Hunan, Sichuan, and Hebei have more capital and labor costs than average because of nonessential pressure of excess production capacity. Labor and capital transforming efficiency are rather high in eastern and southern China where preserve exceeding industry concentration. Capital costs in Guangxi, Inner Mongolia, Jiangxi, and Hubei are higher because of the initial integration of the cement industry within the southeastern and central regions. In respect to environmental cost, the discrepancy is generally small among the various provinces, but is greater in ecological fragile areas such as Tibet, Inner Mongolia, Xinjiang, and Shanxi. Thus, greater attention should be paid to these areas in the future.
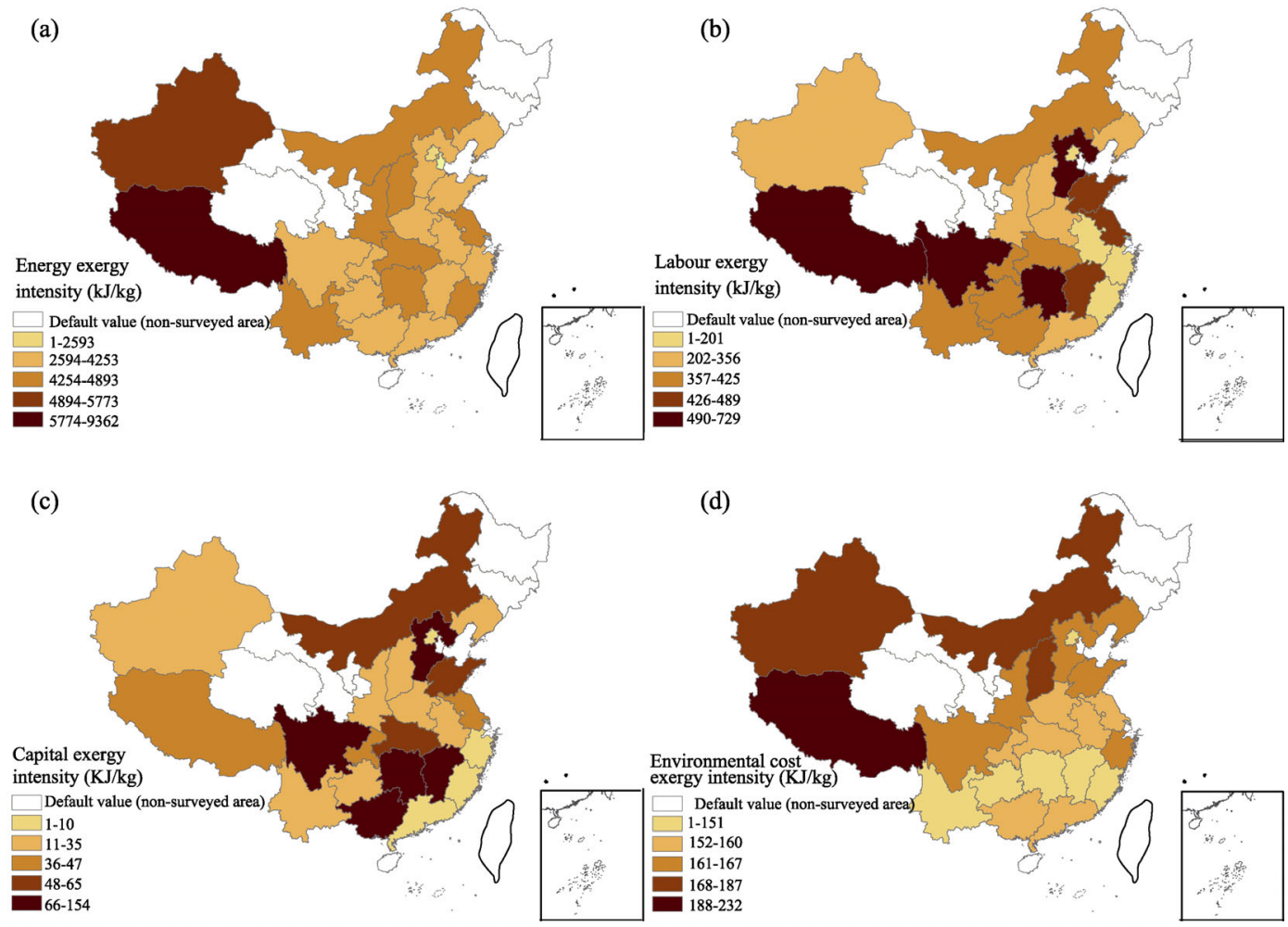

Figure 2 Spatial distribution of exergy intensity for cement production from energy, labor, capital and environmental costs in 2012 by province

\subsection{Spatial agglomeration at the regional level}

Gini coefficients are used to calculate spatial agglomeration at the regional level (Lv and Chen, 2009), where G, G1, G2, G3, and G4 represent the Gini coefficient of extended exergy, energy consumption exergy, labor exergy, capital exergy and environmental cost exergy, respectively, and G0 represents the average value. The result of the Gini coefficient shows that none of the three regions has a high degree of concentration (Table 3). The average Gini coefficient for eastern regions is only 0.337 , and the lowest in the central region is just 0.234 . Based on a comparative analysis, the agglomeration of capital exergy in eastern and western 
regions is displayed, with a Gini coefficient of more than 0.6 and 0.5 , respectively, and just 0.388 in the central region. Additionally, the exergy of energy, labor, and environmental cost are not significant in the agglomeration. The hidden social cost of the cement manufacturing industry presents stronger agglomeration characteristics than energy.

Table 3 Gini coefficient of exergy consumption in three regions in 2012

\begin{tabular}{lcccc}
\hline & & Eastern region & Central region & Western region \\
\hline Gini coefficient given by extended exergy & G & 0.225 & 0.191 & 0.243 \\
Gini coefficient given by energy exergy & G1 & 0.218 & 0.199 & 0.234 \\
Gini coefficient given by labor exergy & G2 & 0.389 & 0.174 & 0.353 \\
Gini coefficient given by capital exergy & G3 & 0.613 & 0.388 & 0.513 \\
Gini coefficient given by environmental cost exergy & G4 & 0.238 & 0.221 & 0.241 \\
The average Gini coefficient & G0 & 0.337 & 0.234 & 0.317 \\
\hline
\end{tabular}

Regarding exergy efficiency, g, g1, g2, g3, g4 and g0 represent the Gini coefficient for extended exergy intensity, energy consumption exergy intensity, labor exergy intensity, capital exergy intensity, environmental cost exergy intensity, and the average value, respectively. The results show that only the Gini coefficient for capital exergy intensity is high enough (Table 4) to display the agglomeration characteristic: $0.586,0.437$ and 0.314 in eastern, central and western regions, respectively. The other Gini coefficients do not reach significance. Therefore, only the capital aspect in hidden social costs presents an obvious agglomeration in China's eastern region from the perspective of energy intensity.

Table 4 Gini coefficient of exergy intensity in three regions in 2012

\begin{tabular}{lcccc}
\hline & & $\begin{array}{c}\text { Eastern } \\
\text { region }\end{array}$ & $\begin{array}{c}\text { Central } \\
\text { region }\end{array}$ & $\begin{array}{c}\text { Western } \\
\text { region }\end{array}$ \\
\hline Gini coefficient given by extended exergy intensity & $\mathrm{g}$ & 0.067 & 0.040 & 0.133 \\
Gini coefficient given by energy exergy intensity & $\mathrm{g} 1$ & 0.065 & 0.029 & 0.147 \\
Gini coefficient given by labor exergy intensity & $\mathrm{g} 2$ & 0.297 & 0.203 & 0.153 \\
Gini coefficient given by capital exergy intensity & $\mathrm{g} 3$ & 0.586 & 0.437 & 0.314 \\
Gini coefficient given by environmental cost exergy intensity & $\mathrm{g} 4$ & 0.023 & 0.033 & 0.078 \\
The average Gini coefficient & $\mathrm{g} 0$ & 0.208 & 0.149 & 0.165 \\
\hline
\end{tabular}

\subsection{Classification based on exergy consumption and exergy intensity}

Using an Euclidean distance model (Rokaya et al., 2008), we computed the distance matrix of the 23 provinces with the variables using SPSS software, including extended exergy consumption and its intensity, energy consumption exergy and its intensity, labor exergy and its intensity, capital exergy and its intensity, environmental cost exergy and its intensity. The results are shown in Table 5.

The classification result shown by the normalized distance matrix (Mei and Fan, 2006) provides a further analysis of the spatial discrepancy. In general, the first dimension is considered the alteration of total consumption including energy and hidden social cost, showing a decreasing trend from left to right. In respect to the second dimension, energy efficiency is 
expressed showing a decreasing trend from top to bottom (Figure 3).

Table 5 Standardized distance matrix (partial)

\begin{tabular}{lccccccccc}
\hline & Chongqing & Zhejiang & Yunnan & Xinjiang & Tibet & Sichuan & Shaanxi & Shanxi \\
\hline Chongqing & 0.000 & 0.214 & 0.143 & 0.158 & 0.623 & 0.604 & 0.048 & 0.091 \\
Zhejiang & 0.214 & 0.000 & 0.203 & 0.160 & 0.754 & 0.720 & 0.136 & 0.178 \\
Yunnan & 0.143 & 0.203 & 0.000 & 0.203 & 0.720 & 0.533 & 0.123 & 0.227 \\
Xinjiang & 0.158 & 0.160 & 0.203 & 0.000 & 0.539 & 0.693 & 0.072 & 0.073 \\
Tibet & 0.623 & 0.754 & 0.720 & 0.539 & 0.000 & 0.969 & 0.613 & 0.557 \\
Sichuan & 0.604 & 0.720 & 0.533 & 0.693 & 0.969 & 0.000 & 0.611 & 0.703 \\
Shaanxi & 0.048 & 0.136 & 0.123 & 0.072 & 0.613 & 0.611 & 0.000 & 0.054 \\
Shanxi & 0.091 & 0.178 & 0.227 & 0.073 & 0.557 & 0.703 & 0.054 & 0.000 \\
\hline
\end{tabular}

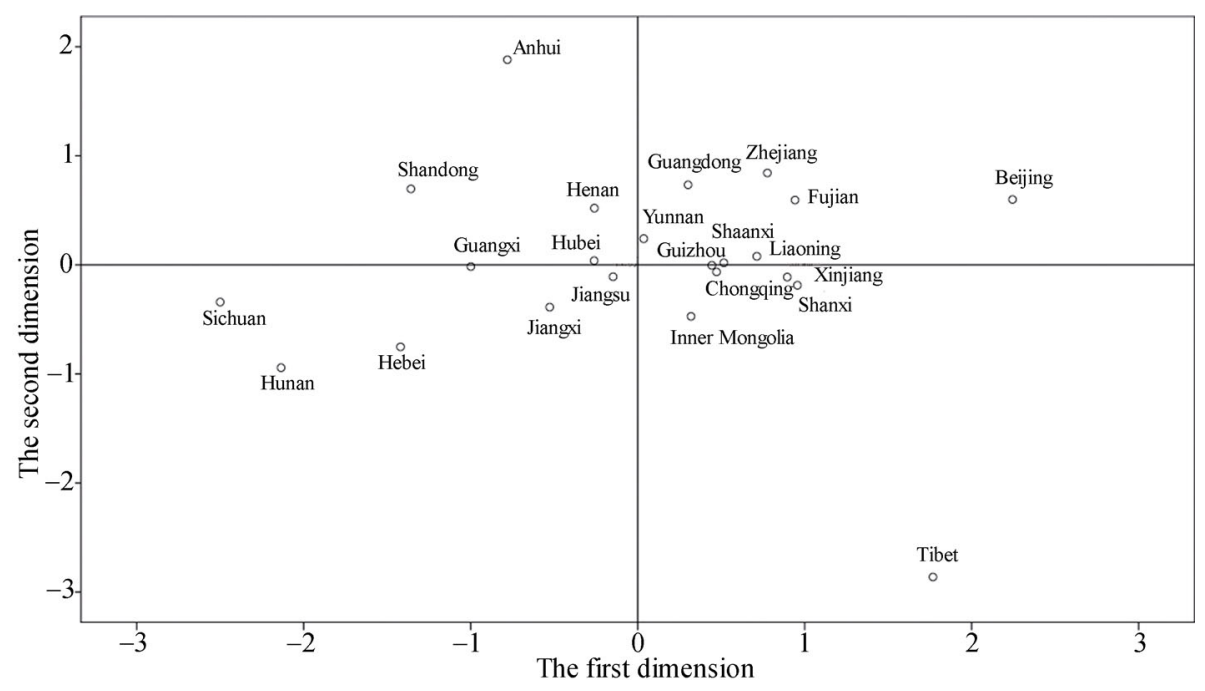

Figure 3 Euclidean distance model diagram for the 23 provinces

To better understand the distance visualization chart and the results of energy consumption and energy intensity, the 23 provinces were divided into 8 categories (Table 6). The first category represents double-high areas including Sichuan, Hunan, and Hebei, with both high energy consumption and energy intensity, not only for energy but also externalities. The second category includes Shandong and Anhui, which are key provinces in cement manufacturing. They have high levels of energy consumption, but are low in energy intensity (i.e., high production with high energy efficiency). The third category includes Jiangxi and Guangxi, which have slightly higher energy consumption and energy intensity than average, especially regarding labor and capital costs. The fourth category includes medium-level areas including Henan, Hubei, Jiangsu, Yunnan, Guizhou, Chongqing, Shaanxi, and Liaoning, with energy consumption and energy intensity levels similar to average levels in cement manufacturing. The fifth category includes Guangdong, Zhejiang, and Fujian, which are all 
located in southeastern coastal areas; their energy consumption and energy intensity there are lower than average and have lower externality costs. The sixth category includes Inner Mongolia, Shanxi, and Xinjiang, with low energy consumption but high energy intensity, indicating lower production levels and lower energy efficiency. Only Tibet is placed in the seventh category, an undeveloped area with very low energy efficiency in cement manufacturing despite its relatively small energy consumption. The eighth category represents Beijing, presenting a double-low area: low energy consumption and low energy intensity, which is the forerunner in China's cement manufacturing industry regarding energy efficiency.

Table 6 Eight patterns for all regions on the basis of exergy use

\begin{tabular}{|c|c|c|}
\hline Category & Provinces & Exergy consumption character \\
\hline The 1st & Sichuan, Hunan, Hebei & $\begin{array}{l}\text { High in extended exergy } \\
\text { High in extended exergy intensity }\end{array}$ \\
\hline The 2 nd & Shandong, Anhui & $\begin{array}{l}\text { High in extended exergy } \\
\text { Low in extended exergy intensity }\end{array}$ \\
\hline The 3rd & Jiangxi, Guangxi & $\begin{array}{l}\text { Slightly higher than average level } \\
\text { Higher labor and capital cost }\end{array}$ \\
\hline The 4th & $\begin{array}{l}\text { Henan, Hubei, Jiangsu, Yunnan, Guizhou, } \\
\text { Chongqing, Shaanxi, Liaoning }\end{array}$ & $\begin{array}{l}\text { Medium-level extended exergy } \\
\text { and extended exergy intensity }\end{array}$ \\
\hline The 5th & Guangdong, Zhejiang, Fujian & $\begin{array}{l}\text { Slightly lower than average level } \\
\text { Lower externality cost }\end{array}$ \\
\hline The 6th & Inner Mongolia, Shanxi, Xinjiang & $\begin{array}{l}\text { Low in extended exergy } \\
\text { High in extended exergy intensity }\end{array}$ \\
\hline The 7th & Tibet & $\begin{array}{l}\text { Quite low in extended exergy } \\
\text { Backward in energy efficiency }\end{array}$ \\
\hline The 8th & Beijing & $\begin{array}{l}\text { Quite low in extended exergy } \\
\text { Advanced in energy efficiency }\end{array}$ \\
\hline
\end{tabular}

\subsection{Driving forces of exergy use in the cement manufacturing industry}

The results show a significant correlation between total energy consumption and investments in the design capacity of newly increased production lines, the gross assets of enterprises above a designated size, the number of enterprises the above designated size, the main operating revenue and gross profit (with significance level of less than 0.01), and fixed assets investment (with a significance level of less than 0.05). However, total energy consumption has a weaker correlation with the number of technology patents in the cement manufacturing industry, N20 and N100, indicating that scale, profit, and investment are the main factors influencing total energy consumption in the cement manufacturing industry (Table 7). However, the total energy intensity presents the highest correlation with N100, passing the significance test, while the correlation of N20 is slightly lower than that of N100 but still much higher than that of the other explanatory variables. Thus, the industry concentration factor can explain the spatial distribution of energy intensity of China's cement manufacturing industry. The significant negative correlation of energy intensity to industry concentration means that a higher degree of industry concentration can lead to a lower energy intensity and higher energy efficiency in the cement manufacturing industry. While, the correlation between energy intensity and technology, scale, profit and investment decrease. 
Table 7 Correlation of determinants of exergy use distribution for the cement manufacturing industry

\begin{tabular}{|c|c|c|c|c|}
\hline \multirow{3}{*}{ Explanatory variables } & \multicolumn{4}{|c|}{ Spatial difference of exergy use for the cement manufacturing industry } \\
\hline & \multicolumn{2}{|c|}{ Extended exergy } & \multicolumn{2}{|c|}{ Extended exergy intensity } \\
\hline & Correlation & $\mathrm{N}$ & Correlation & $\mathrm{N}$ \\
\hline \multicolumn{5}{|l|}{ Scale } \\
\hline $\begin{array}{l}\text { The number of enterprises above } \\
\text { designated size }\end{array}$ & $0.779 * *$ & 0.000 & -0.293 & 0.175 \\
\hline $\begin{array}{l}\text { The gross assets of enterprises above } \\
\text { designated size }\end{array}$ & $0.821 * *$ & 0.000 & -0.282 & 0.193 \\
\hline \multicolumn{5}{|l|}{ Profit } \\
\hline The main operating revenue & $0.797 * *$ & 0.000 & -0.273 & 0.207 \\
\hline The gross profit & $0.780 * *$ & 0.000 & -0.258 & 0.235 \\
\hline \multicolumn{5}{|l|}{ Investment } \\
\hline The fixed assets investment & $0.504 *$ & 0.014 & -0.057 & 0.795 \\
\hline $\begin{array}{l}\text { The designed capacity of newly in- } \\
\text { creased production line being invested }\end{array}$ & $0.973 * *$ & 0.000 & -0.323 & 0.133 \\
\hline \multicolumn{5}{|l|}{ Technology } \\
\hline $\begin{array}{l}\text { The number of technology patent in } \\
\text { cement manufacturing industry }\end{array}$ & 0.354 & .097 & -0.312 & 0.147 \\
\hline \multicolumn{5}{|l|}{ Industry concentration } \\
\hline $\mathrm{N} 20$ & 0.149 & 0.497 & -0.383 & 0.071 \\
\hline N100 & 0.228 & 0.295 & $-0.439^{*}$ & 0.036 \\
\hline
\end{tabular}

* significant at 0.05 confident level, ** significant at 0.01 confident level.

\section{Discussion}

In general, our results indicate that the main factor influencing the efficiency of exergy use in China's cement manufacturing industry is industry concentration. Therefore, to promote efficiency and reduce total exergy consumption in this particular industry, Zhejiang and Beijing should be presented as examples, as they both have a very high degree of industry concentration. In contrast, Sichuan, Hunan, and Hebei have the potential for energy conservation, which could be realized with improvements in industry concentration. Guizhou, Yunnan, Chongqing, Tibet, Xinjiang, Shanxi, and Inner Mongolia in the west are still at the stage of decentralized management and the integration of the cement industry is not fully developed. Furthermore, technology is relatively underdeveloped in these areas, and if industry concentration and technical level can be improved then the cement manufacturing industry will experience significant improvements and optimization.

In contrast, although the indicators of scale, profit, investment, and technology have just a small effect on the efficiency of exergy use in the cement manufacturing industry, they all enjoy a positive interaction with industry concentration. Furthermore, the role of influencing factors is not the same in all provinces. For example, the advantage of technology and scientific research significantly affects the efficiency of exergy use in Beijing, with spatial spillovers. The elimination of limited production capacity in Guangdong plays a positive role in improving the efficiency of exergy use. Anhui benefits from economies of scale relying on the Hailuo Group, which is the largest supplier of clinker in Asia. Regarding Guangxi, although located in the west, it enjoys significant overseas investment because of the Pearl River Delta (water transportation). Thus, it has a higher level of efficiency of exergy use 
compared with other western provinces. Additionally, economic development, industry orientation, financial situation, and other factors (Marcon and Puech, 2003; Puga, 2010) can affect competition between different cement enterprises, and the spatial patterns of exergy use in cement manufacturing industry are eventually shaped by these factors.

\section{Conclusions}

In this paper, the EEA method was introduced to calculate exergy use in the cement manufacturing industry in China's 23 provinces, including not only energy but also externalities. A spatial pattern was demonstrated at both provincial and regional levels, and the 23 provinces were then divided into 8 categories. We identified the factor with the greatest influence on the efficiency of exergy use. The main conclusions are as follows:

(1) Invisible social costs including labor, capital, and environmental cost consumed approximately $10 \%$ of the total exergy use in China's cement manufacturing industry, whereas the energy element accounted for about $90 \%$. Although the eastern region had almost the same exergy consumption as the west, the efficiency of exergy use was $10 \%$ higher than that in the western region.

(2) The provinces with high exergy consumption in the cement manufacturing industry were mainly distributed in the eastern region with Anhui and Shandong at the core, and in the western region Sichuan had the highest rate. Furthermore, the distribution of efficiency decreased from east to west.

(3) With respect to the different elements, the exergy consumption of labor and capital was highlighted in Hebei, Shandong, Sichuan, Hunan, and Guangxi provinces, whereas the environmental cost was high in overcapacity provinces. Additionally, the efficiency of exergy use of energy, labor, and capital decreased from east to west, and capital was significantly agglomerated in the eastern region because of a more perfect cooperation mechanism.

(4) With respect to factors influencing exergy use in the cement manufacturing industry, the industry concentration factor currently plays a key role in efficiency in China, whereas the impacts of scale, profit, investment, and technology factors were comparatively weak on efficiency.

(5) Under the pressure of overcapacity and environmental protection, China's government should act to improve industry concentration in Sichuan, Hunan, and Hebei to unleash the clear potential for energy conservation in the cement industry. Additionally, greater attention must be paid to the environmental cost in overcapacity provinces including Zhejiang, Guangdong, Henan, Anhui and Shandong, also in ecological fragile provinces including Tibet, Inner Mongolia, Xinjiang, and Shanxi.

\section{References}

ASKCI, 2014. The clinker production data of pre-calcining kiln in China by province. http://www.askci.com/ news/201303/21/211525881807.shtml. (in Chinese)

CDC, 2012. The log data set of ground climate in China. http://cdc.cma.gov.cn/. (in Chinese)

China Cement Association (CCA), 2006-2011. China Cement Almanac. Beijing: China Building Industry Press, 390-600. (in Chinese)

Cohen J P, Paul C J M, 2005. Agglomeration economies and industry location decisions: The impacts of spatial and industrial spillovers. Regional Science and Urban Economics, 35(3): 215-237.

Costanza R, Cumberland J H, Daly H et al., 2002. An Introduction to Ecological Economics. Florida, USA: Taylor \& Francis, Chemical Rubber Company Press, 183-193.

Daly H E, Farley J, 2010. Ecological Economics. 2nd ed. Principles and Applications. Washington, DC, USA: 
Island Press, 106-125.

Doloreux D, Shearmur R, 2012. Collaboration, information and geography of innovation in knowledge intensive business services. Journal of Economic Geography, 12: 79-105.

Ghemawat P, Thomas C, 2008. Strategic interaction across countries and multinational agglomeration: An application to the cement industry. Management Science, 54(12): 1980-1996.

Hasanbeigi A, Menke C, Therdyothin A, 2010. The use of conservation supply conversion energy policy and economic analysis: The case study of Thai cement industry. Energy Policy, 38(1): 392-405.

$\mathrm{Hu}$ B, 2009. A comparative study on China's inter-provincial human development index [D]. Changchun: Jilin University, 10-21. (in Chinese)

IEA-ETSAP, 2010. Cement production. http://iea-etsap.org/web/HIGHLIGHTS\%20PDF/ I03_cement_June\% 202010_GS-gct\%201.pdf.

Jebaraj S, Iniyan S, 2006. A review of energy models. Renewable and Sustainable Energy Reviews, 10(4): 281-311.

Lv W, Chen W, 2009. Manufacturing industry enterprises location choice and the urban spatial restructing in Nanjing. Acta Geographica Sinica, 64(2): 142-152. (in Chinese)

Marcon E, Puech F, 2003. Evaluating the geographic concentration of industries using distance-based methods. Journal of Economic Geography, 3: 409-428.

Mei C, Fan J, 2006. Method of data analysis. Beijing: Higher Education Press, 55-156. (in Chinese)

National Bureau of Statistics (NBS), 2013. Economic statistical yearbook of the People's Republic of China. Beijing: China Statistics Press, 3-398. (in Chinese)

National Bureau of Statistics (NBS), 2013. http://data.stats.gov.cn/. (in Chinese)

Phylipsen G J M, Blok K, Worrell E, 1997. International comparisons of energy efficiency-Methodologies for the manufacturing industry. Energy Policy, 25(7-9): 715-725.

Puga D, 2010. The magnitude and causes of agglomeration economies. Journal of Regional Sciences, 50(1): 203-219.

Qi B, 2010. The impact analysis research on energy saving factors in China. Master degree thesis of Dalian University of Technology, 58-72. (in Chinese)

Rocco M V, Colombo E, Sciubba E, 2014. Advances in exergy analysis: A novel assessment of the extended exergy accounting method. Applied Energy, 113: 1405-1420.

Rokaya M, Atlam E, Fuketa M et al., 2008. Ranking of field association terms using co-word analysis. Information Processing and Management, 44(2): 738-755.

Saxena J P, Saxena A, Pahuja A et al., 1995. Energy efficiency through technological improvements. World cement, 26(6): 62-67.

Scheuer A, Ellerbrock H G, 1992. Possible ways of saving energy in cement production. Zement-Kalk-Gips, 45(5): $222-230$.

Sciubba E, 2003. Extended exergy accounting applied to energy recovery from waste: The concept of total recycling. Energy, 28: 1315-1334.

Sciubba E, 2011. A revised calculation of the econometric factors $\alpha$ and $\beta$ for the extended exergy accounting method. Ecological Modelling, 222: 1060-1066.

Sciubba E, Bastianoni S, Tiezzi E, 2008. Exergy and extended exergy accounting of very large complex systems with an application to the province of Siena, Italy. Journal of Environmental Management, 86: 373-382.

Seckin C, Sciubba E, Bayulken A R, 2012. An application of the extended exergy accounting method to the Turkish society, year 2006. Energy, 40: 151-163.

Shen L, Gao T, Zhao J et al., 2014. Factory-level measurements on $\mathrm{CO}_{2}$ emission factors of cement industry in China. Renewable and Sustainable Energy Review, 34: 337-349.

Sogut M Z, 2012. A research on exergy consumption and potential of total $\mathrm{CO}_{2}$ emission in the Turkish cement sector. Energy Conversion and Management, 56: 37-45.

Sogut M Z, Oktay Z, Hepbasli A, 2009. Energetic and exergetic assessment of a trass mill processin a cement plant. Energy Conversion and Management, 50(9): 2316-2323.

Szargut J, Morris D R, Steward F R, 1987. Exergy analysis of thermal, chemical and metallurgical processes. New York, NY, USA: Hemisphere Press, 66-108.

The People's Bank of China (PBC), 2012. The annual statistics of 2012. http://www.pbc.gov.cn. (in Chinese)

Valero A, Lozano M A, Munoz M, 1986. A general theory of exergy saving: I. On the exergetic cost. Computer-Aided Engineering and Energy Systems, 3: 1-8.

Worrell E, Laitner J A, Ruth M et al., 2003. Productivity benefits of industrial energy efficiency measures. Energy, 28(11): 1081-1098.

Worrell E, Martin N, Price L, 2000. Potentials for energy efficiency improvement in the US cement industry. Energy, 25(12): 1189-1214.

Zeng X, 2006. Energy consumption status and energy saving potential of cement industry. Chinese Cement, 20(3): 16-21. (in Chinese)

Zhu M, 1988. Exergy Analysis on Energy System. Beijing: Tsinghua University Press, 56-89. (in Chinese)

Zook M A, 2002. Grounded capital: Venture financing and geography of the Internet industry, 1994-2000. Journal of Economic Geography, 2: 151-177. 